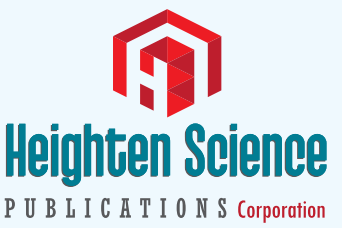

ISSN

2637-3793
*Address for Correspondence: Jorge F Cameselle Teijeiro, MD-PhD, Clinical Oncology Research Center, ADICAM, Travesía de Vigo $n^{\circ} 2-2$ C Vigo 36206, Spain, Email: videoprimaria@mundo-r.com

Submitted: 23 December 2018

Approved: 28 December 2018

Published: 31 December 2018

Copyright: @ 2018 Calheiros-Cruz T, et al. This is an open access article distributed under the Creative Commons Attribution License, which permits unrestricted use, distribution, and reproduction in any medium, provided the original work is properly cited

Keywords: McArdle's disease (Glycogen Storage Disease type V); Rare disease; Myophosphorylase emzyme; Glycogen phosphorylase enzyme; Muscle glycogenosis; CPK; GSDV

Check for updates

\title{
McArdle's Disease (Glycogen Storage Disease type V): A Clinical Case
}

\author{
Calheiros-Cruz $\mathrm{T}^{1}$, Caamaño-Vara $\mathrm{MP}^{2}$, Villar-Fernández $\mathrm{B}^{3}$, \\ Ruibal-Azevedo $\mathrm{J}^{1}$, Cameselle-Cortizo L ${ }^{1}$, Cameselle-Arias $\mathrm{M}^{1}$, \\ Charro Gamallo $M E^{1}$, Turienzo-Pacho $F^{1}$, Yera Acosta $A^{1}$ and \\ Cameselle-Teijeiro JF ${ }^{1 *}$
}

${ }^{1}$ Clinical Oncology Research Center, ADICAM, Vigo and Cangas, Spain

${ }^{2}$ Bachelor in Biology and Nursing, Researcher in Rare Diseases, Santiago de Compostela, Spain ${ }^{3}$ Northamptom Community College, Pennsylvania, USA

\section{Resume}

McArdle's Disease, or Glycogen Storage Disease Type $V$, is the result of a deficiency in one of the enzymes responsible for the metabolism of glycogen in the body. Individuals with this disease, lack or produce very small concentrations of the myophosphorylase or glycogen phosphorylase enzyme.

McArdle's disease is a metabolic and recessive genetic disease caused by a mutation on the PYGM gene located on chromosome 11q13. This gene is responsible for the synthesis of the myophosphorylase (or glycogen phosphorylase) enzyme. It is the most common form of muscular glycogenesis. We present here the clinical case of a 35 years old woman diagnosed with McArdle's disease at the age of 21 after a visit to a Neurologist. It was confirmed that the patient had shown symptoms of this disease at least 10 years before definitive diagnosis: intolerance to exercise, asthenia and muscular weakness. In this report we describe the different signs and symptoms of the disease, as well as the tests performed to confirm the diagnosis by muscle biopsy and genetic analysis. McArdle's disease is classified as a rare disease and often its diagnosis is delayed due to a lack of knowledge about its symptoms and signs. Our intention is to make, with the description of our clinical case, the information about this disease more available to physicians to prevent future misinterpretations and delayed diagnosis. A medical documentary we have created on "McArdle's Disease" can be seen in YouTube using the following links: https://youtu.be/HAhoZ7jxz7Q (English version) and https://youtu.be/uZopzSHOI20 (Spanish version).

\section{Introduction}

McArdle's disease or Glycogen Storage Disease Type V (GSDV) is caused by a deficiency in one of the enzymes responsible for the metabolism of glycogen in the body. Individuals with this disease, lack or produce very small concentrations of the myophosphorylase (or glycogen phosphorylase) enzyme. A mutation in the gene responsible for the production of this enzyme can cause the deficiency. To date, around 150 different disease-causing variants in PYGM have been reported [1], with approximately half being missense variants, $\sim 18 \%$ deletions, $\sim 13 \%$ nonsense variants, $\sim 11 \%$ splice site variants and the remainder duplications or insertion/ deletion variants $[2,3]$. The majority of variants are located within exons and all result in severely reduced or absent myophosphorylase enzyme activity, often as a result of nonsense-mediated decay [4].

This disease is mostly characterized as a myopathy, affecting primarily the muscle tissue. The myophosphate enzyme is essential for obtaining energy, as it's deficiently in individuals with the mutation affects primarily the capacity of the skeletal muscle to 
perform physical exercises, therefore most patients show intolerance to exercise. This is the most common sign of muscular glycogenesis, with very characteristic clinical and laboratory features [5].

The prevalence of this disease is currently unknown. Martin et al. [6], indicated that the first signs seem to appear during the first decade of life, but it varies, thus increasing the risk of misdiagnosis and diagnostic delays.

\section{Clinical Case}

A 35 years old woman was first diagnosed in a Neurology's consultation at the age of 21, with a delayed diagnosis of at least 10 years. The clinical signs included: intolerance to exercise, asthenia, muscular weakness and episodes of rhabdomyolysis. The diagnosis was established by a muscular biopsy, showing vacuolar myopathy with negative myophosphorylase linked to McArdle's disease or glycogen storage disease type $\mathrm{V}$ (Figures 1,2). The genetic study was performed 12 years after the clinical diagnosis: A homozygotic mutation in the PYGM gene was found, pathogenic variant c.C148T:p.R50X.

For many years, the symptoms of this disease were misinterpreted as "lack of motivation to physical exercise" and it was classified during different medical visits as indepent symptoms of a psychological disorder. However, during the time previous to the muscular biopsy, the levels of CK (creatine kinase) were already elevated at rest (1.400 UI/L) and during crisis of rhabdomyolysis increased to very elevated values ( $40.000 \mathrm{UI} / \mathrm{L})$, that decreased after intense IV therapy, and fortunately did not prorogue renal failure at the time.

\section{Discussion}

McArdle's Disease is a rare disease of unknown prevalence, caused by a mutation in the PYGM gene, located on chromosome 11q13, producing a deficit in the muscular glycogen phospholysase enzyme, or myophosphorylase. There is no detectable activity of this enzyme in the majority of the affected invididuals, but in a small percentage of the patients, the enzymatic activity gets reduced to $20-30 \%$ of the normal values and it is not totally absent. GSDV is inherited as an autonomic recessive condition, which means that to have it, one should inherit one copy of the mutated gene from each
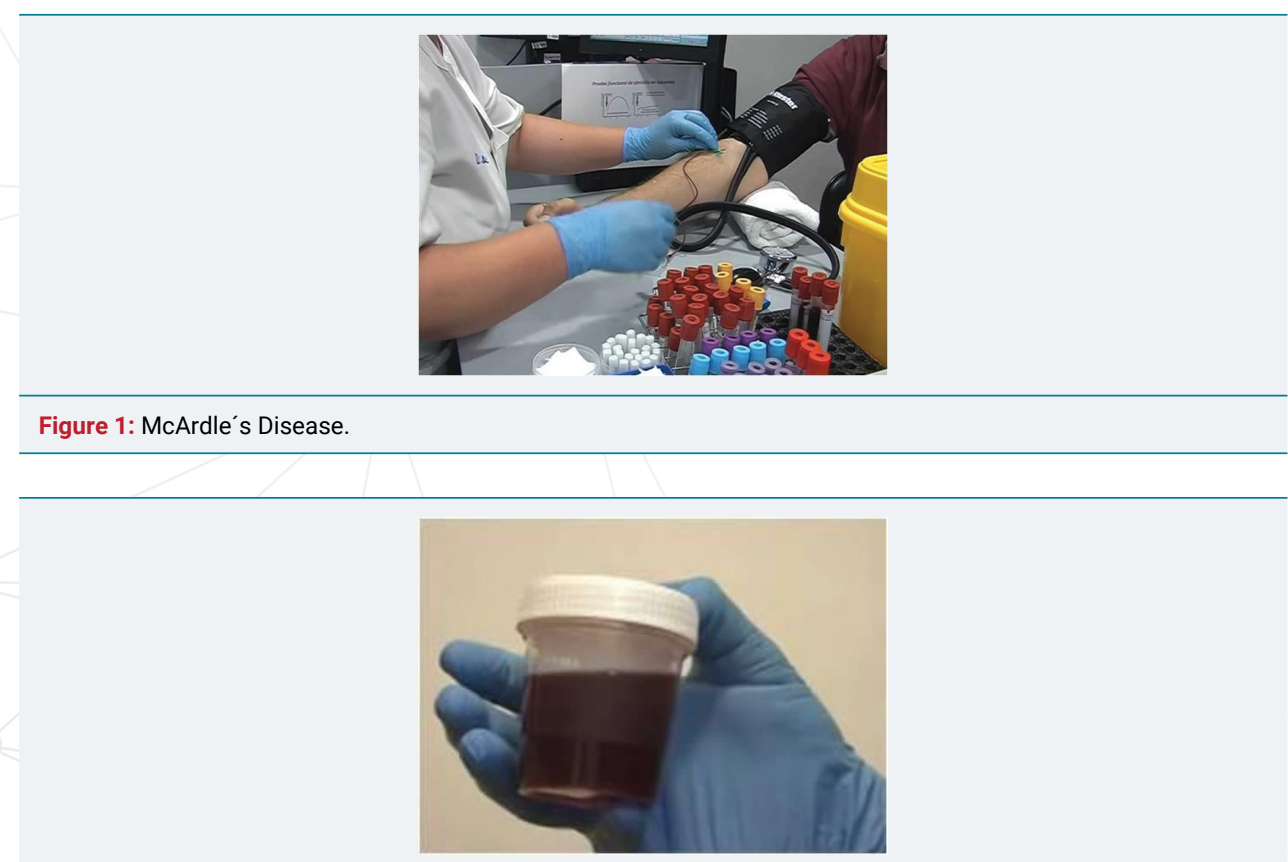

Figure 2: The urine is dyed red but there are no red bloodcells in its sediment. 
parent, with a combined probability of being affected of $25 \%$. Siblings of an affected individual have a $50 \%$ probability of being carriers and a $25 \%$ of being not affected [7].

This disease usually debuts during the first decade of life. The clinical symptoms are similar to any other metabolic myopathy: fatigue during exercise (mostly during the first 10 minutes), myalgias, muscle cramps, muscle weakness and crisis of rhabdomylysis that cannot be explained [8]. There is often observed a decrease in symptoms after a brief period of rest, and this phenomenon is called "second wind", characterized by a partial recovery due to the decrease in cardiac frequency during the rest period, allowing the individual to recover and tolerate exercise for a longer period of time [9]. Recently, it has also been observed that younger individuals with McArdle's disease often present problems with mastication and oral motor function skills [10].

We believe that it is very important to acknowledge the excessive recurrence of erroneous diagnosis, inadequate medical interventions and delayed prognosis often associated with this disease. Despite the fact that this disease could be easily diagnosed if known by the physician, the reality is that many cases have been misdiagnosed during childhood and the correct diagnosis is rarely done before adult age (age 33 average diagnoses). The most common misdiagnosis included "growth pains" and "psychiatric/psychological origin", more commonly in women than men. Consequently, all these patients receive an incorrect explanation of their symptoms and an incorrect treatment, therefore delaying appropriate assessment and adequate prognosis [11].

The appearance of symptoms after exercise, particularly the isometric contraction of muscles after weight lifting, is well known in McArdle's disease. Brady et al. [12], also found that even emotionally-intense situations can result in rhabdomyolysis in patients affected with this disease, but this is not well known by many physicians and could contribute to delays in diagnosis.

GSDV is the most common alteration of all the muscle glycogenesis, with a very characteristic clinical and laboratory features (5): (a) elevated levels of CK (creatin kinase) in a persistent way in the serum and at rest, with values oscillating around $1000 \mathrm{IU} / \mathrm{L}$ (reference value $<200 \mathrm{UI} / \mathrm{L}$ ) and (b) absence of changes in the plasma concentration of lactate during the ischemic forearm exercise test. This test is based on the determination of plasma concentrations of lactate and ammonium at the start of hand exercises and after two minutes. The hand exercises consist of opening and closing the hand of the arm where a spyhngomanometer is located. Each isometric contraction of the hand lasts one second, and around 30 contractions are expected in one minute. In healthy individuals, the increase of lactate during this exercise is three to five times more with respect to the basal or control level. In patients with GSDV however, the increase in lactate in not observed, and instead, a characteristic "flat curve of lactate" is obtained, with the lactate to ammonium ratio decreasing after exercise. It has been also found that in GSDV the values of ammonium in plasma greatly increase after exercise, and therefore measuring its concentration could be as informative as measuring the concentration of lactate [6].

Considering that the non-ischemic forearm exercise test has the same diagnostic value as the ischemic test, today many physicians have abandoned the use of the ischemic test due to the following inconveniences: false positives in weak or poorly-motivated individuals, low specificity (the test can give positive values due to any other types of blockages of glycogenosis or glucolysis), appearance of myalgias, muscle cramps and possible myoglobinuria's crisis or spontaneous compartment syndrome $[13,14]$.

A cycle test is a physiological test that can also be used for the diagnosis of GSDV. This test records the cardiac frequency to detect the pathognomonic heart rate response observed in the second wind phenomenon. This response involves a notable increase in cardiac frecuency ( $>30-40$ heart beats/min) during the first 10 minutes in 
all individuals with GSDV, when performing an exercise test with moderate intensity, in conjunction of symptoms of mialgia and exercise-induced muscle cramps and pain, that improve after a brief rest period or when exercise intensity is reduced. This exercise test is sensitive, specific and simple to perform, with no posibilities of false positives [13].

The analysis of the activity of the myophosplorylase enzyme in muscular biopsies allows for diagnoses. The definitive diagnosis is confirmed by molecular genetic testing for the PYGM gene, which codifies for the muscle type of the glycogen phospholysase enzyme. Currently, this is the only gene known to be associated to GSDV (with p.Arg50Ter and p.Gly205Ser as the more common pathogenic variants).

Although there is no cure available for this desease, the affected individuals benefit from moderate aerobic exercise and training (for example walking or riding a bike) to increase their cardiorespiratory and cell oxidation capacities. An active life style can also improve their poor bone health, mostly because of its action on the lean body mass [15]. The ingestion, before exercise, of sport drinks containing simple carbohydrates increases the tolerance to exercise and can protect against exerciseinduced rhabdomyolysis [6].

Despite the fact that the mayority of patients with McArdle's disease present symptoms including fatige, cramps and episodes of myoglobinuria, the diagnose is often delayed by several decades, and many patiens with rhabdomyolysis continue to be undiagnosed. Half of the affected patients present a massive increase of creatine kinase (CK) and a crisis of rhabdomyolysis with myoglobinuria (dark urine) after intense exercise, caused by the necrosis of the muscular fibers. This situation can increase the risk of acute renal failure and be potentially fatal. This prognosis becomes favorable when massive rhabdomyolysis is prevented [7].

\section{References}

1. Taylor RL, Davis M, Turner E, Brull A, Pinos T, et al. Clinical utility gene card for McArdle disease. European Journal of Human Genetics. 2018; 26: 758-764. Ref.: https://goo.gl/nXGVCj

2. Nogales-Gadea G, Brull A, Santalla A, Andreu AL, Arenas J, et al. McArdle disease: update of reported mutations and polymorphisms in the PYGM gene. Hum Mutat. 2015; 36: 669-678. Ref.: https://goo.gl/yttcfi

3. Vieitez I, Teijeira S, Fernandez JM, San Millan B, Miranda S, et al. Molecular and clinical study of McArdle's disease in a cohort of 123 European patients. Identification of 20 novel mutations. Neuromuscul Disord. 2011; 21: 817-823. Ref.: https://goo.gl/J67zuz

4. Nogales-Gadea G, Rubio JC, Fernandez-Cadenas I, Garcia-Consuegra I, Lucia A, et al. Expression of the muscle glycogen phosphorylase gene in patients with McArdle disease: the role of nonsensemediated mRNA decay. Hum Mutat. 2008; 29: 277-283. Ref.: https://goo.gl/aSPq79

5. Park HJ, Shin HY, Cho YN, Kim SM, Choi YC. The significance of clinical and laboratory features in the diagnosis of glycogen storage disease type v: a case report. J Korean Med Sci. 2014; 29: 1021-1024. Ref.: https://goo.gl/aVqDtU

6. Martín MA, Lucía A, Arenas J, Andreu AL. Glycogen Storage Disease Type V. Adam MP, Ardinger HH, Pagon RA, et al., editors. GeneReviews ${ }^{\circledR}$ [Internet]. Seattle (WA): University of Washington, Seattle; 1993-2018.2006 Apr 19 [Updated 2014 Jun 26]. Ref.: https://goo.gl/Ybqc9r

7. Quinlivan R, Martinuzzi A, Schoser B. Pharmacological and nutritional treatment for McArdle disease (Glycogen Storage Disease type V). Cochrane Database Syst Rev. 2014: CD003458. Ref.: https://goo.gl/ZHECTs

8. Keel BR, Brit M. McArdle's disease: a clinical review and case report. Tenn Med. 2013; 106: 33-37. Ref.: https://goo.gl/5xAtJi

9. Porcelli S, Marzorati M, Belletti M, Bellistri G, Morandi L, et al. The "second wind" in McArdle's disease patients during a second bout of constant work rate submaximal exercise. J Appl Physiol (1985) 2014; 116: 1230-1237. Ref.: https://goo.gl/foShQf

10. Kouwenberg CV, Voermans NC, Quinlivan R, van den Engel-Hoek L. Mastication and Oral Motor 
Function in McArdle Disease: Patient Reported Complaints. J Neuromuscul Dis 2018; 5: 353-357. Ref.: https://goo.gl/pfQPzX

11. Scalco RS, Morrow JM, Booth S, Chatfield S, Godfrey R, et al. Misdiagnosis is an important factor for diagnostic delay in McArdle disease. Neuromuscul Disord. 2017; 27: 852-855. Ref.: https://goo.gl/iDMQbu

12. Brady S, Godfrey R, Scalco RS, Quinlivan RM. Emotionally-intense situations can result in rhabdomyolysis in McArdle disease. BMJ Case Rep. 2014; 2014. pii: bcr2013203272. Ref.: https://goo.gl/3exr7F

13. Kazemi-Esfarjani P, Skomorowska E, Jensen TD, Haller RG, Vissing J. A nonischemic forearm exercise test for McArdle disease. Ann Neurol 2002; 52: 153-159. Ref.: https://goo.gl/qtv3hk

14. Triplet JJ, Goss DA, Taylor B. Spontaneous Compartment Syndrome in a Patient with McArdle Disease: A Case Report and Review of the Literature. JBJS Case Connect. 2017; 7: e49. Ref.: https://goo.gl/N8UUYe

15. Rodríguez-Gómez I, Santalla A, Díez-Bermejo J, Munguía-Izquierdo D, Alegre LM, et al. A New Condition in McArdle Disease: Poor Bone Health-Benefits of an Active Lifestyle. Med Sci Sports Exerc. 2018; 50: 3-10. Ref.: https://goo.gl/Gz9mDB 